\title{
ReNature: creating the first nature-based solutions compendium in the Mediterranean
}

\author{
Anna Sapundzhieva $a^{\ddagger}$, Mario V Balzan§, Judita Tomaskinova§, Leticia De Santis§, Marcus John Collierl, \\ Jean Williams', Lynn Dicks ${ }^{\top}$, Miriam Grace ${ }^{\#}$, Davide Geneletti ${ }^{\circledR}$, Iliyana Demirova ${ }^{\ddagger}$ \\ $\ddagger$ Pensoft Publishers, Sofia, Bulgaria \\ $\S$ Malta College of Arts, Science and Technology, Paola, Malta \\ | Trinity College Dublin, Dublin, Ireland \\ II University of Cambridge, Cambridge, United Kingdom \\ \# University of East Anglia, Norwich, United Kingdom \\ a University of Trento, Trento, Italy
}

Corresponding author: Mario V Balzan (mario.balzan@mcast.edu.mt)

Reviewable $\quad v 1$

Received: 14 Oct 2020 | Published: 29 Oct 2020

Citation: Sapundzhieva A, Balzan MV, Tomaskinova J, De Santis L, Collier MJ, Williams J, Dicks L, Grace M,

Geneletti D, Demirova I (2020) ReNature: creating the first nature-based solutions compendium in the

Mediterranean. Research Ideas and Outcomes 6: e59646. https://doi.org/10.3897/rio.6.e59646

\section{Abstract}

The ReNature nature-based solutions compendium (http://renature-project.eu/ compendium) is an open-source collection, which contains data on nature-based solutions in Malta. Initially collecting information only about Malta, the compendium is growing to include submissions from across the whole Mediterranean region. The development of an open-source compendium plays an essential role in the co-creation of knowledge, and fostering capacity-building at a national and international level, which are some of the key objectives of ReNature. By sharing existing and successful implementation of nature-based solutions, the platform is giving examples of good practices for practitioners and the research community. This paper reviews the process of the development of the ReNature open-source compendium.

\section{Keywords}

biodiversity, ecosystem services, nature-based solutions, sustainable development, sustainable development goals, urban ecology 


\section{Preface}

ReNature aims to create a transition from theoretical knowledge and good practices in advanced research institutions to actual future application. Part of this work includes the creation of an open access compendium which will be shared openly online to enable the co-creation of knowledge, foster capacity-building at a national and international scale and share the developed tools as an example of good practice for practitioners and the research community. The compendium is integrated into the official ReNature website (www.renature-project.eu/compendium).

\section{Summary}

This document explains the process of preparation of the open-source compendium including the method of gathering of information (first about Malta and then the Mediterranean basin) and the compilation of the data into a more user-friendly format with specifically defined search capabilities.

\section{Identifying the ReNature Nature-based solutions Compendium}

\section{case studies}

The collection of information for the ReNature nature-based solutions open-source compendium has followed a two-stage process, which entailed:

1. Online searches for local examples of the implementation of nature-based solutions in Malta. Identified initiatives were then contacted and asked to provide further information.

2. Dedicated interviews with key stakeholders during which they were asked to provide the ReNature team with further information about the implementation of nature-based solutions, the limitations and the opportunities for uptake of naturebased solutions initiatives.

\section{Online searches and invitation to submit case-studies to the ReNature Nature-based solutions Compendium}

An initial search for nature-based solutions in Malta was carried out via the search engine Google and using the following search terms:

- nature-based solutions,

- green roofs,

- green walls,

- noise and wind pollution,

- trees planted,

- climate change, and

- health and well-being. 
Each term was entered individually along with the word Malta. This search returned many responses relating to nature-based solutions, climate change mitigation and adaptation from companies, nongovernmental organizations and national authorities. In many cases, the identified initiatives had websites and social media (e.g. Facebook) pages which were consulted with prior to contacting them individually. In some cases, the initiatives were contacted via a designated email address or, otherwise, through social media.

The ReNature team also invited key stakeholders to submit examples of nature-based solutions which have been applied to alleviate species environmental or socio-economic challenges in Malta. For this purpose, the stakeholders were provided with a promotional flyer containing information about nature-based solutions and inviting stakeholders to submit case-studies to the ReNature compendium (Fig. 1). The flyer detailed what information was requested by the project including examples along with contact details for the submission of the case-studies. The flyer was also distributed to stakeholders and attendees at a Training Course and Thematic Workshop held at the Malta College of Arts, Science and Technology (MCAST), Paola (Malta), in May 2019, and uploaded to the ReNature website, and distributed via the project social media accounts.
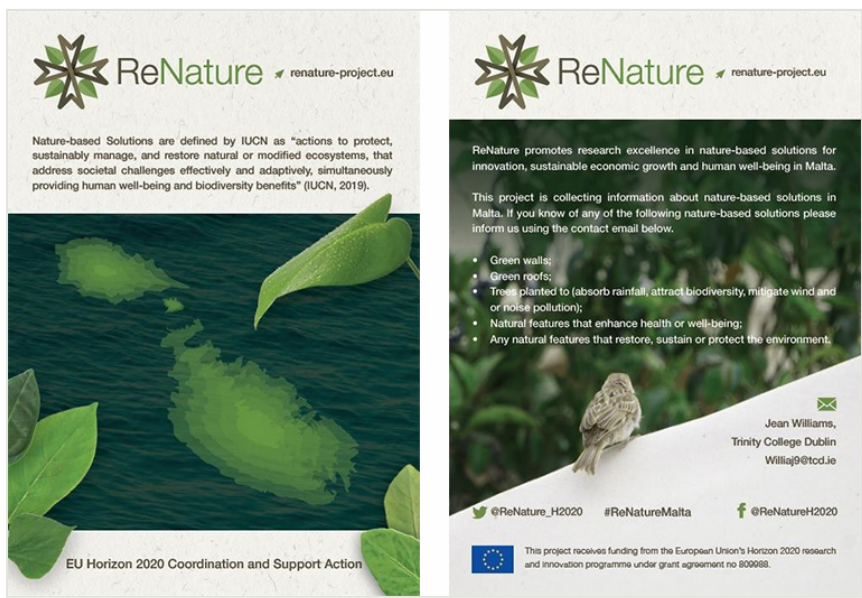

Figure 1. doi

The ReNature nature-based compendium flyer was sent and handed out to key stakeholders to invite them to submit case-studies for inclusion in the online compendium.

Respondents were generous with their information and in some instances, responses provided the name of other individuals and/or organizations, institutions and/or nongovernmental organizations who had installed nature-based solutions.

\section{Stakeholder interviews}

Key stakeholders from policy and business were identified from the Maltese Islands, and were invited to participate in semi-structured interviews. A total of 7 semi-structured interviews with key stakeholders working in the environmental, water, planning, 
infrastructure, culture, and tourism sectors in Malta were carried out. The interview questionnaire and methodology were approved by the ethics committee of the MCAST and informed consent was obtained from all participants. The participating authorities were considered as being key players in the promotion of mainstreaming and uptake of naturebased solutions at a national level. In the case of business stakeholders, we have identified large businesses that make a significant contribution to the national GDP and which already have an ongoing environmental programme, focusing on monitoring of environmental impacts and the mitigation of these, and have a history of corporate social responsibility action that promotes improvement in societal well-being and the environment. These interviews followed on a workshop with environmental stakeholders from Malta, Cyprus, Sicily and Sardinia to identify knowledge needs to implement naturebased solutions in Mediterranean islands. The workshop followed a modified Delphi process to identify existing knowledge needs, as described in Grace et al. (accepted). During the workshop, the need for a more precise definition of nature-based solutions, the identification of nature-based solutions that are adapted to the Mediterranean climate, or which can be retrofitted to existing building and built-up areas, approaches that increase the use of nature-based solutions in urban plans, and the cost-benefit analysis of naturebased solutions were identified as the priority knowledge needs for the mainstreaming of nature-based solutions.

The interview questions focused on understanding the usefulness of existing definitions in guiding organisations to identify nature-based solutions, the identification of nature-based solutions implemented by the organisation, the specific challenges tackled and the reasons for selecting a location when establishing nature-based solutions, and the relation to the sustainable development goals (SDGs). Results obtained from the interviews are used to provide evidence and guidance about the potential impacts and contributions of the tools and methods presented here in linking science to actual practice of nature-based solutions implementation. Stakeholders were asked to comment on how their specific nature-based solutions examples could feed into individual SDGs. Information they provided was included in the compendium, along with scientific and other references located during literature searches.

Stakeholders were also shown the compendium format on the ReNature website and given a chance to comment on the design and the information. All comments were positive and encouraging. Feedback from the authorities indicated that the compendium can provide an important tool for policy-making as it "will help us deliver the message as policy makers and prove that it can work". Another stakeholder working in the environmental sector commented that the compendium "provides a platform for collaboration" whilst a stakeholder from the cultural sector also commented that the compendium is a tool that is "useful for knowledge sharing", particularly if presenting "good practices and initiatives linked to (urban) greening" and to promote further collaboration through participation in European projects. Another stakeholder, this time from the business sector, commented that the ReNature nature-based solutions compendium is "helpful to see what others have 
done, what the problems are and the solutions". A detailed analysis of the interviews responses is provided by Balzan et al. (submitted), which

1. evaluates stakeholders' perspectives, and challenges and opportunities for the implementation of nature-based solutions,

2. provides practical guidance for facilitating knowledge exchange and nature-based solution co-creation across the science-policy interface, and

3. provides an overview of methods that may be used for evidencebased interventions that apply nature-based solution in Malta.

The data retrieved from (1) the online term searches and (2) stakeholder participation was reviewed, and whenever each submitted case-study was considered as a nature-based solution, as defined by the IUCN (Cohen-Shacham et al. 2016), or as an example of green infrastructure that leads to cobenefits this was included in the ReNature Nature-based Solutions Compendium. In the compendium a distinction between nature-based solutions and other forms of green infrastructure is made. Literature searches were carried out using Google Scholar and the websites of the authorities and other stakeholders in Malta to obtain further information about the specific case-study and its potential co-benefits. The bibliography used in the development of the compendium consisted of both grey and published scientific literature and is shown in Appendix 1 and on the case-study web pages. Information retrieval for was mainly limited to Malta or, in case of wider challenges such as climate change, at regional Mediterranean level.

\section{Design and structure of the Open-source compendium}

The ReNature Compendium is published on the project website (http://renatureproject.eu/ compendium). It consists of an interactive world map, search \& filter box, as well as a list of results, which link to case study descriptions. The search \& filter box, located on the Compendium landing page, constitutes of a search field and five filters (Fig. 2). Users can filter results by the following criteria:

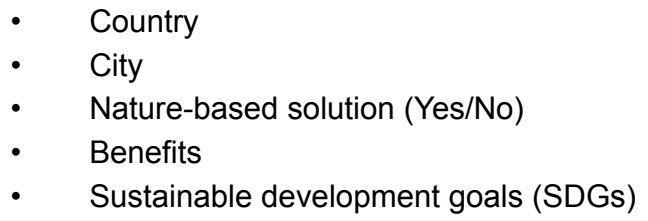

Once users have selected their desired criteria, the respective results are shown in a list below (Fig. 3). To visualize the case studies, there is an interactive world map (Fig. 4), integrated on the Compendium main page. Each case study coordinates are pinned on the map, which enables users to easily find and select a case study by its location. Upon mouse click, location pointers show a link to each case study description (Fig. 5). 


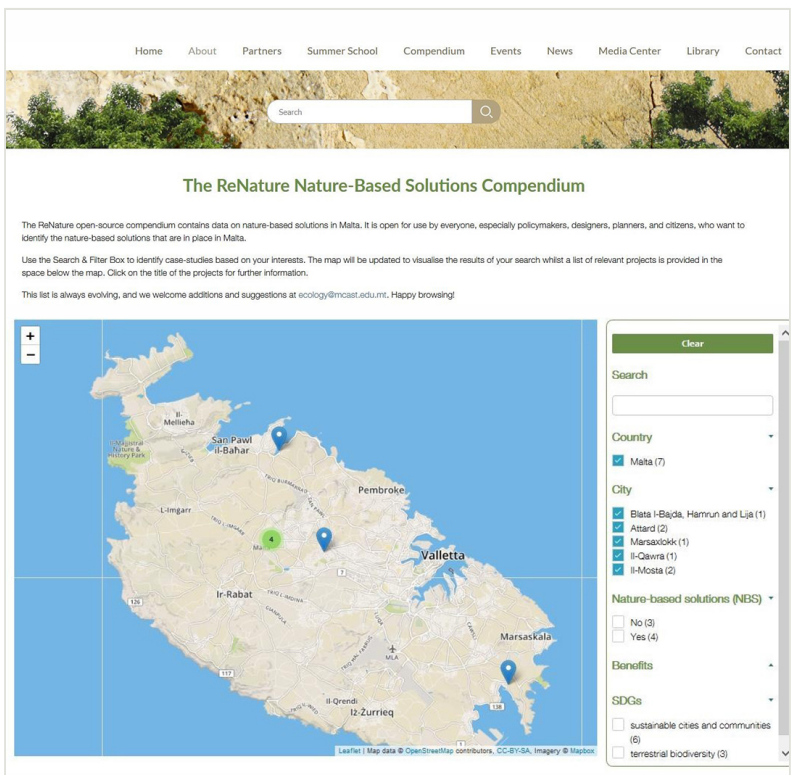

Figure 2. doi

ReNature Compendium search and filter fields.

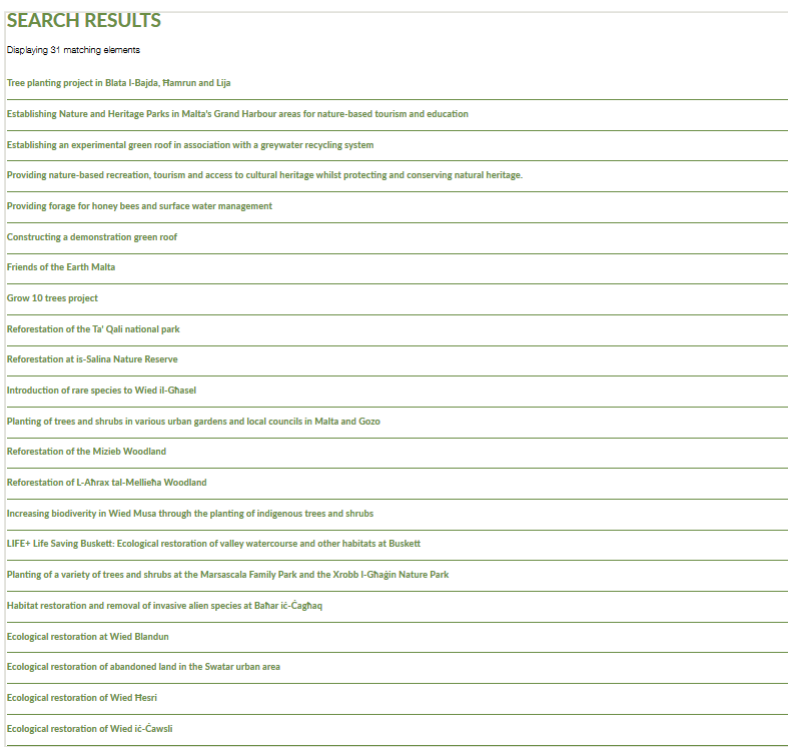

Figure 3. doi

Compendium results list. 

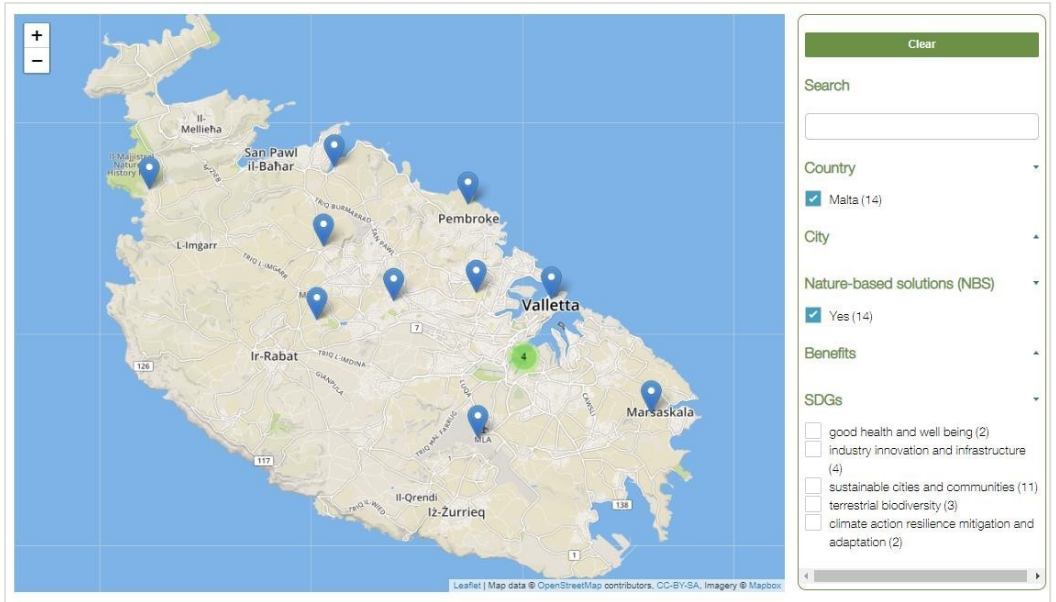

Figure 4. doi

ReNature Compendium map with nature-based solutions.
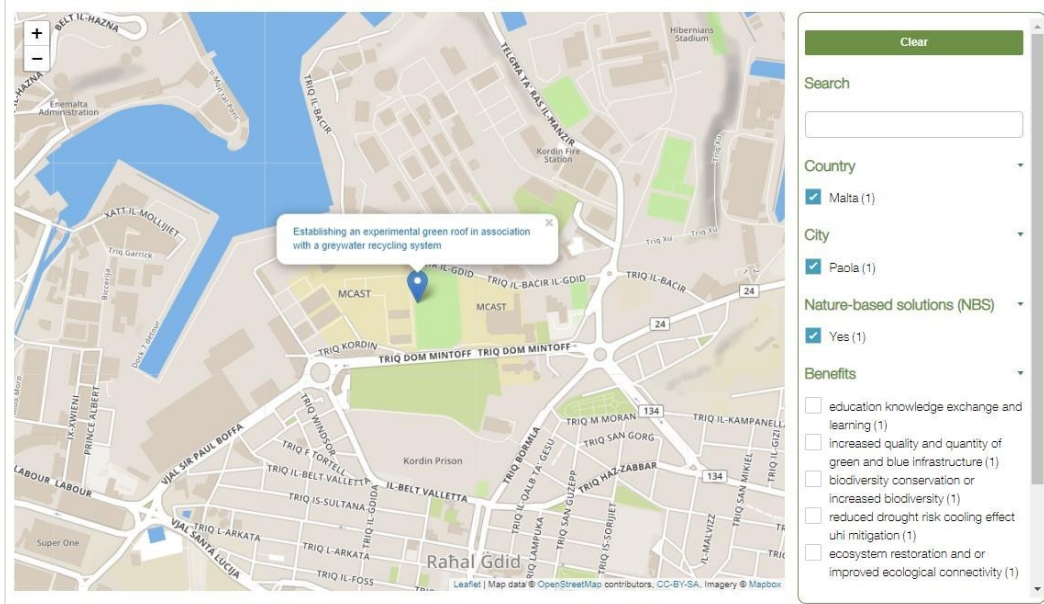

Figure 5. doi

Location pointers, which link to case studies.

For each case study, there is a dedicated page, where the user can find detailed information about it (Fig. 6). This information consists of a description, including the case study's objectives, data about the country, city, coordinates, as well as implementation period. Information about the initiator of the initiative is provided. Each page contains a list of benefits, problems (if any) and SDGs. 


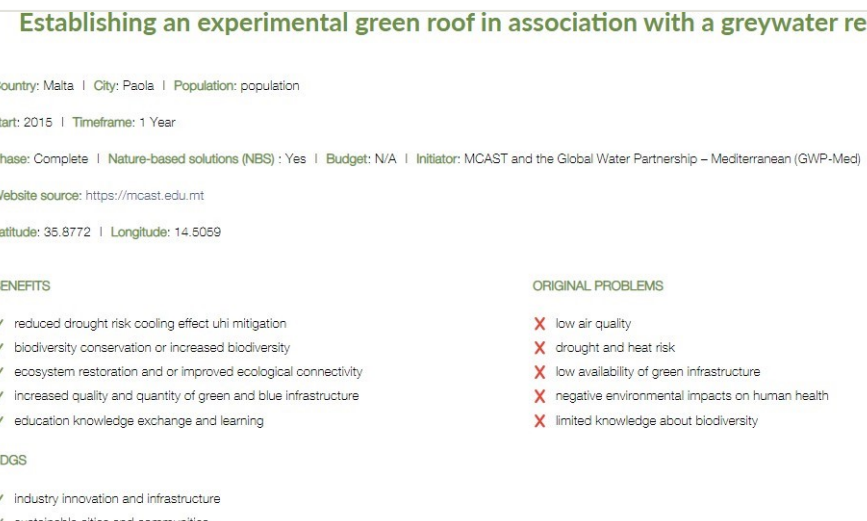

Figure 6. doi

ReNature Compendium case study page.

\section{Establishing a platform for collaboration through the ReNature Nature-based Solutions Compendium}

The first published version of the Compendium database consists of 31 entries but it is currently being expanded, and stakeholders and the interested public from Malta and the Mediterranean are invited to submit additions and suggestions at ecology@mcast.edu.mt.

The publication of the ReNature Nature-based Solutions Compendium will be communicated on the ReNature project website and through the social media accounts of the project. As the coordinator of the project, the MCAST is also expected to disseminate this project outcome with collaborating institutions and key stakeholders in Malta, whilst these will be invited to submit suggestions and other case-studies for inclusion in the compendium. Hence the ReNature Nature-based Solutions Compendium will be considered as a dynamic document that will continue to be updated until the end of the project through the addition of case-studies to showcase good practices, support evidence based implementation of nature-based solutions and to establish a platform for collaboration for Malta and the Mediterranean region.

Open-source data generated in the creation of the ReNature nature-based solutions compendium will be linked to the nature-based solutions knowledge sharing online tools to ensure the long-term availability of this project outcome.

\section{Conclusion}

A dedicated open-source compendium was created, permitting the co-creation of knowledge through open-source innovation. This compendium will be shared openly online to enable the co-creation of knowledge and foster capacity-building around Malta and later, the Mediterranean. 


\section{Acknowledgements}

The ReNature project receives funding from the European Union's Horizon 2020 research and innovation programme under grant agreement No 809988.

\section{References}

- $\quad$ Balzan MV, Grace M, Collier M, Geneletti D, Longato D, Sapundzhieva A (submitted) Evidence-based implementation of nature-based solutions in Mediterranean cities.

- Cohen-Shacham E, Walters G, Janzen C, Maginnis S (2016) Nature-based solutions to address global societal challenges. IUCN: Gland, Switzerland, 97. https://doi.org/ 10.2305/IUCN.CH.2016.13.en

- $\quad$ Grace M, Balzan M, Collier M, Geneletti D (accepted) Priority knowledge needs for implementing nature-based solutions in the Mediterranean islands. Manuscript submitted for publication. Environmental Science \& Policy. 